Alisa Mahmutović

INSTITUT ZA JEZIK U SARAJEVU

Sarajevo, Bosna i Hercegovina

alisamahmutovic77@gmail.com

https://doi.org/10.17234/9789531755139.19

\title{
INTERTEKSTUALNO MOTIVIRANI POREDBENI FRAZEMI S ANIMALISTIČKOM KOMPONENTOM
}

\begin{abstract}
U radu se analiziraju poredbeni frazemi konstruirani s animalističkom sastavnicom, a kao teorijski okvir poslužila nam je poststrukturalistička teorija intertekstualnosti. Ona polazi od stajališta da svaki diskurs kreira značenje kroz interakciju s drugim diskursima, što nam je pri analizi frazema kao jezičnih jedinica utemeljenih u kulturnom modelu određenog društva bilo iznimno korisno. Osim toga, ova teorija se zasniva i na važnosti konteksta svakog teksta, pa se govori o kontekstu u užem i širem smislu, gdje se pod kontekstom u širem smislu podrazumijeva cjelokupna kultura, što je opet nezaobilazno kada govorimo o frazeologiji, budući da pod kulturom ovdje podrazumijevamo sve ono što je jedno društvo stvorilo, sve što se u tom društvu mora znati ili vjerovati da bi se djelovalo na prihvatljiv način. Odnosno, polazimo od kulture onako kako ju je definirao Goodenough (1964), koji između kulture i znanja stavlja znak jednakosti, stoga analizirati frazeme znači suočavati se sa bitnim obilježjima vlastite kulture.
\end{abstract}

Ključne riječi: poredbeni frazemi, intertekstualnost, tekst, kultura, kontekst

\section{Uvod}

Naše iskustvo podjednako potječe iz onoga što smo doživjeli, onoga što smo pročitali, kao i onoga što smo čuli, zato kažemo da je kultura u kojoj živimo i u kojoj se razvijamo, veoma važna $i$, možda, određujuća u našem razumijevanju svijeta i odnosa u njemu. Ona formira naš svjetonazor, i uokvirena je u tekstovima u znatno većoj mjeri nego što smo toga svjesni, pa je ovo istraživanje, upravo zato, fokusirano na frazeme intertekstualnog porijekla u bosanskom jeziku. Pritom polazimo od frazema kao potencijalne jedinice teksta koja svojom funkcionalnošću te svojim pragmatičkim i semantičkim obilježjima omogućava ovakav pristup. Budući da je pojam kulture preširok i neprecizan jer obuhvaća raznorodna društvena polja djelovanja, bilo je nužno uvođenje preciznije terminologije koja bi objasnila određene primjere. U tom smislu, kako ćemo vidjeti, pojam intertekstualnosti pokazao se funkcionalnim, što je znatno pridonijelo analizi određenih frazemskih jedinica, naročito onih za čije je razumijevanje bilo potrebno poznavanje šireg konteksta: tradicije, običaja, historije, religijskih i drugih praksi. Time se izravno pokazalo koliko se oslanjamo na ono što smo naslijedili, odnosno naučili. Jer kultura ne podrazumijeva samo nasljeđivanje, već i učenje. Tekstovi pohranjeni u zajedničkom kulturnom iskustvu, kao i oni kojima smo svakodnevno izloženi, predstavljaju rezervoar slika pomoću kojeg nosimo i kreiramo nove jezične sklopove i slike prema vlastitoj kulturnoj logici. A želimo li te usvojene slike rekonstruirati u bilo kom smislu, frazeologija nam je u tom postupku nezaobilazan instrument. 


\section{Teorijski okvir}

\subsection{Poredbena frazeologija}

Pošto se istraživanja tiču frazema koji u svojoj strukturi imaju animalističku sastavnicu, pojavljuje se nekoliko nezaobilaznih pitanja u vezi s tim. Prvo: šta nam govori izbor životinja u frazeologiji; šta nam životinje govore o nama, a time i o našoj kulturi? Odnosno, da li se radi o nekom nasumičnom izboru iz životinjskog svijeta, ili to ipak ima određenog smisla i sistema? Drugo: može li se utvrditi ili pretpostaviti izvor frazeologizacije? I treće: koji su to primarni tekstovi iz kojih se posuđuje i kakav status imaju u kulturi? Kako smo se ovom prilikom odlučili za strukturni tip poredbenih frazema, napomenut ćemo nešto o njihovim bitnim karakteristikama, kao i o razlozima koji su nas vodili pri odabiru. Dakle, za nas je ovdje od presudne važnosti bila činjenica da su poredbeni frazemi izrazito frekventan frazemski strukturni tip, $i$ to ne samo u književnosti nego i u svakodnevnom govoru. Važno ih je razlikovati od semantičke stilske figure poređenja tipa simile, iako imaju istu ili sličnu strukturu jer se i u jednom i u drugom javlja poredbena čestica kao, mada u strukturi poređenja umjesto nje može stajati i poput ili nalik (Katnić-Bakaršić 2001). Strukturno-semantički tip ovih frazema nije moguće svesti na jedan obrazac, zato govorimo o više strukturnih tipova gdje su dva osnovna tipa tzv. dvodijelni i trodijelni. ${ }^{1}$ Dvodijelni strukturni tip je znatno malobrojniji, dok je trodijelni i mnogobrojniji i frekventniji. Trodijelni poredbeni frazemski tip podrazumijeva strukturu: $\mathrm{A}+\mathrm{B}+\mathrm{C}$, gdje je (A) (comparandum), kao (comparatum) i B (tertium comparationis). Prvi, (A) dio, predstavlja komponentu koja se uspoređuje, a koja prethodi poredbenoj čestici kao (segmentu B), a poredbena čestica prethodi komponenti s kojom se uspoređuje. Iako su poređenja i poredbeni frazemi strukturno vrlo bliski, poređenje je utemeljeno na bližoj semantičkoj vezi između dijela A i dijela B. Drugim riječima, poređenje čine poređenjem zajednički sememi ova dva dijela, dok, s druge strane, frazemi ne moraju imati, i često nemaju, nijedan zajednički sem. Poređenja se konstruiraju u govornom procesu, a poredbeni frazemi se reproduciraju kao gotove, neizmijenjene cjeline. Također, C-dio, kod većine poredbenih frazema, nosi samo denotativno značenje, a značenju cijelog frazema pridonosi konotativnim značenjem, tj. sistemom uobičajenih asocijacija ili simbolike vezane uz određen sem (Omazić 2002). Jedna od osnovnih funkcija poredbene frazeologije je potenciranje značenja dijela A, koji uglavnom dolazi u svom leksičkom značenju, a C-dio može imati i samo funkciju intenzifikatora. Osim toga, postoje i poredbeni frazemi kod kojih slikovitosti nema. ${ }^{2}$ Dok se, s druge strane, u stilističkoj literaturi često i sama metafora definira kao skraćeno poređenje, odnosno, kao poređenje u kojem je ostavljen samo korelat (Katnić-Bakaršić 2001: 321-333). I na koncu, treba naglasiti da se poređenje i poredbeni frazemi razlikuju i prema upotrebi. Svako poređenje kao stilska figura teži originalnosti i često ga je teško naći izvan određenog diskursa i žanra, dok frazeme, zapravo, mo-

\footnotetext{
O tome detaljnije: Fink- Arsovski 2002: 10-35.

Prema Fink-Arsovski 2006: 6.
} 
žemo upotrijebiti u bilo kom diskursu: u kolokvijalnom govoru, stručnom ili naučnom diskursu, kao i administrativnom, pravnom, medijskom i bilo kojem drugom. Drugim riječima, poredbene frazeme i poređenja razlikujemo prema njihovoj prirodi i upotrebi, mada je sasvim jasno da su mnogi poredbeni frazemi poređenja po porijeklu, koja su vremenom i frekventnošću, prešla u frazeološki fond. I sasvim je sigurno da izvore nastanka frazema uvijek treba tražiti u prirodnoj i društvenoj sredini u kojoj određeni jezik funkcionira, kao i u nasljeđu (Tanović 2000: 14). Motivirani narodnim običajima i religijskim praksama, frazemi su vrijedni reprezenti kulture u kojoj su nikli i u kojoj žive. Njihovo je značenje neodvojivo od kulturne podloge, zato polazimo upravo od kulture u širem smislu.

\subsection{Identifikacija kulture}

Kako ističe Goodenough (1964: 36-39), teško je opisati bilo koju kulturu ukoliko se opisuju samo ponašanja, ekonomska ili ceremonijalna dešavanja koja su joj svojstvena. Sa istraživačkog ili teorijskog aspekta nužno je tragati za unutarnjim značenjem jer kultura nije samo ono što opažamo i zapažamo već je mnogo više u odnosima na implicitnoj razini. Svaki je pristup istraživanju kulture otežan budući da se prvo definicija kulture postavlja kao problem, jer postoji mnoštvo definicija, a i sama riječ kultura vremenom je mijenjala značenje. ${ }^{3} \mathrm{~S}$ obzirom na ove činjenice, u ovom radu ćemo govoriti o kulturi u širem smislu, što podrazumijeva sva njezina aktuelna značenja: antropološko (način života), civilizacijsko (fizički i umni rad) i bihejvioralno (obrasci ponašanja). Odnosno, polazimo od naučno općeprihvaćene i antropološki zasnovane definicije kulture, kako kaže Bugarski, kao zbira različitih normi ponašanja, vjerovanja, načina općenja, sistema vrijednosti, svih onih historijski izraslih eksplicitnih $i$ implicitnih obrazaca koji u svako vrijeme djeluju kao potencijalni vodiči u djelatnostima i ponašanju članova društvene zajednice (Bugarski 2013). Drugim riječima, koncept kulture postavljen je kao sistem koji strukturira i usmjerava ljudsko iskustvo, pri kojem svaka kultura na različite načine predstavlja stvarnost i stvara različite interpretativne obrasce pomoću kojih se reprezentira i tumači svijet, a temeljni mehanizam interpretacije je jezik, budući da je svaka kultura stvorena jezikom i u jeziku. Sapirovski rečeno, želimo li otvoriti vrata neke kulture moramo imati ključ odnosno jezik, a njegovu leksičko-frazeološku razinu u prvom redu. Frazeološki fond jezika, vrlo razvidno, može pokazati na koji način neko društvo usvaja određene navike mišljenja ili, kako ih Murdock zove, „kolektivne ideje“ (Murdock 1965: 114). Tim prije, ako frazeme posmatramo kao kulturne fenomene, što s obzirom na njihovo određenje i temeljna obilježja oni sasvim sigurno i jesu. A kako samim frazemima pristupamo kao minitekstovima, utvrđujemo kojim se intertekstualnim postupcima u poredbenoj frazeologiji služi naša kultura u konstruiranju određenih kulturnih fenomena. Time se jasnije pokazuje u kojoj su mjeri frazemi, kao ustaljene jezične jedinice, utemeljeni u kulturi, u kojoj je već uređeno znanje o svijetu; znanje koje je organizirano unutar određe-

Tako Terry Eagleton govori o prilično rijetkom semantičkom obratu koji je direktno skopčan sa historijskim. 
ne kulture, i koje služi za razumijevanje i kategorizaciju svakog novog iskustva. Zato pri svakoj analizi i interpretaciji određene jezične jedinice, moramo polaziti od konteksta $u$ najširem smislu. Upravo zbog ovako tijesnog odnosa između frazeologije i kulture, čini se da je za istraživanje i interpretaciju vrlo pogodna teorija intertekstualnosti jer, shvatimo li kulturu kao jedan dikurs, ili tekst sastavljen od mnoštva drugih, u kojem se stalno redistribuiraju novi tekstovi na osnovu postojećih, kao i drugi kodovi, ritmički obrasci, dolazimo do intertekstualnosti kao jednog od važnih postupaka u nastanku frazeologije. A ovim će se istraživanjem samo ilustrirati različite intertekstualne strategije u nastanku frazema.

\subsection{Teorija intertekstualnosti}

Budući da u ovom istraživanju frazema polazimo od frazema kao minitekstova, pojam intertekstualnosti je, ovom prilikom, posuđen iz teorije književnosti, u koju su ga uveli poststrukturalisti, koji pojmom univerzum diksursa mijenjaju perspektivu odnosa i granica različitih tekstova i diskursa unutar kulture/kultura. ${ }^{4}$ Drugim riječima, o intertekstualnosti možemo govoriti na mjestima gdje se tekst referira na neki drugi tekst jer je, prema Juliji Kristevoj, svaki tekst asimilacija ili transformacija nekog ranijeg teksta ili djela, a slično misli i Roland Barthes. ${ }^{5}$ Taj koncept je smislen i legitiman jer puno bolje opisuje fenomen o kojem se govori. On prevazilazi već uvriježeni pojam kulture, kojim se obično pojašnjava ovakvo porijeklo frazema. ${ }^{6}$ Štaviše, još uvijek je izvan svake discipline, i izrazito polivalentan, o čemu svjedoči njegovo razvijanje u pogledu tekstualno-teorijske, tekstualno-deskriptivne i kulturno-kritičke perspektive. Zbog toga ima smisla razvijati ga i u frazeološko-teorijskom smislu, naročito u pravcu definiranja i profiliranja određenih koncepata. Pozajmljivanje je iznimno korisno kod frazema kod kojih je za razumijevanje bitno poznavanje šireg konteksta: historije, tradicije, običaja, religijskih praksi i sl., jer se, u okviru ovog učenja, ukida granica između različitih tekstova i polja diskursa. Osim toga, pojam intertekstualnosti ne relativizira samo granice između tekstova već i između tekstova i svijeta u kome živimo jer ga spoznajemo i doživljavamo upravo preko njegove tekstualne reprezentacije. A kako su ovi (intertekstualni) postupci u direktnoj vezi sa društvenim poretkom, vidjet ćemo šta sve sadržajno ostaje zabilježeno u kulturi putem frazeologizacije, odnosno kako spoljni, društveni i kulturološki okivri rukovode u onome što će ostati. ${ }^{7}$ Preciznije, postojeći koncepti i konvencije kreiraju se na osnovu u kulturi sačuvanih tekstova i jedinica tekstova. No, samim tim što govorimo o frazemima preuzetim iz drugih tekstova i diskursa, a koji cirkuliraju u našoj kulturi, znači da koncept intertekstualnosti ovdje podrazumijevamo u širem smislu. Drugim ri-

\footnotetext{
$4 \quad$ O tome detaljnije vidjeti: Kristeva (1967).

Vidjeti: Barthes (1982).

${ }_{6}$ U frazeološkoj se literaturi o porijeklu frazema uglavnom govori o potrebi poznavanja konteksta za razumijevanje značenja, gdje se ponegdje precizira samo na koji se kontekst misli: historijski, tradicijski i sl.

7 Ovdje kulturološke i društvene okvire zovemo spoljnjim jer se kulturno pamćenje njima rukovodi, a manje pitanjem unutrašnjih kapaciteta i upravljanja.
} 
ječima, naša je analiza kulturološki i semantički usmjerena jer se nastoji utvrditi eventualno porijeklo i motiviranost. Odnosno, usmjeravamo se na istraživanje nenamjerne produkcije intertekstualnosti koja, do sada, nije bila predmet lingvističkih istraživanja. ${ }^{8}$

\section{Analiza korpusa}

Korpus istraživanja čine poredbeni frazemi objavljeni u rječniku poredbenih frazema (Kao frazeološki rječnik), u kojem je zabilježeno preko 600 najfrekventnijih frazema u bosanskom jeziku, gdje ih je oko 80 sa animalističkom komponentom u strukturi, odnosno to je broj životinja koje se javljaju, a broj frazema je mnogo veći. ${ }^{9} \mathrm{~S}$ obzirom na vrstu životinje i sve što je prethodno rečeno, analizirana građa pokazuje da se ovi poredbeni frazemi mogu podijeliti u dvije grupe. Prvu bi činili frazemi koji u svojoj strukturi imaju tzv. domaće životinje, poznate, bliske glodare i insekte. Dakle, one koje su bile i jesu dio naše svakodnevice i u kojima je iznimno važan lokalni kontekst. Tako u prvoj grupi imamo sljedeće životinje: pas, mačka, ptica, miš, konj, ovan, mrav, vrana, zec, krava, riba, kokoš, ovan, pčela, pile, svinja. U drugoj su grupi frazemi koji u svojoj strukturi imaju divlje životinje, gmizavce ili insekte s kojima nismo bili u neposrednom kontaktu. Odnosno, znanja o njima utemeljena su u posrednom iskustvu, a najčešće su u frazeologiju dospjeli preko drugih tekstova ili diskursa, umjetničkih, zabavnih ili znanstvenih. Oni su ostvareni različitim intertekstualnim tehnikama, pa smo ih prema tome i podijelili u nekoliko skupina:

a) Frazemi vizuelne referencije su poredbeni frazemi čija je animalistička komponenta ušla u strukturu putem slike. U njima se pojavljuju npr.: lav, slon ili majmun. Takvi su: boriti se kao lav 'jako se boriti', bacati se kao lav 'vrijedno i strastveno raditi', zatim biti kao slon 'biti debeo, ogroman', zijevati kao slon 'zijevati jako otvorenih usta; prenes. buljiti' te biti kao majmun 'biti hiperaktivan, uznemiren; neozbiljan, nestalan; prenes. biti ružan'. Ove frazeme u zajedničku grupu svrstava medij. Na ovaj se način sačuvao vizuelni dojam, koji je ovim putem dobio i svoju vanjsku manifestaciju neophodnu za uspješnost njihova cirkuliranja i prijenosa u kulturi. U istu grupu išao bi i frazem biti kao ptica trkačica 'biti vrijedan, stizati sve, više stvari odjednom; biti neuhvatljiv'. Formiran je prema poznatom i popularnom crtanom filmu iz osamdesetih godina dvadesetog stoljeća, koji se davao u redovnom terminu prije centralnog dnevnika, ali i u programskim pauzama jer je bio kraći od drugih. ${ }^{10}$ Pretpostavljamo da je upravo

$\overline{8}$ Barem do sada nismo naišli na lingvističke studije ili članke koji bi istraživali ili objašnjavali nenamjernu produkciju intertekstualnosti. Uglavnom se istražuju namjerni intertekstualni postupci u različitim diskursima.

9 Naročito kada se radi o domaćim životinjama. Tako se npr. mačka, pas, krava javljaju u više frazema pa se može reći: biti slobodan kao ptica, jesti kao ptica, kružiti kao ptica itd.

10 Crtani film (The Road Runner Show) snimljen je u 60-ima, a na jugoslovenskim se televizijama prikazivao u 80-ima. Iako nije kraći u odnosu na druge crtane filmove iz tog perioda (Duško Dugouško, Tom i Jerry, Mornar Popaj...), on se, budući da nije imao govorni dio, već se cijeli davao u slikama, vrlo često puštao u kratkim pauzama, odnosno davane su samo određene situacije. 
vrijeme emitiranja bilo presudno $\mathrm{u}$ formiranju frazema jer se, $\mathrm{u}$ vrijeme njegova emitiranja, porodični život i slobodno vrijeme u kući drugačije organiziralo. Drugim riječima, dolazi iz vremena industrijskog društva i tradicionalne porodice kada se vrijeme, mnogo više, strukturiralo prema potrebama porodice kao zajednice, a manje u smjeru individualnih sloboda članova porodice. No, svejedno, svi ovi frazemi posredovani su slikom, tako da se vrlo osnovano može pretpostaviti da su se životinje u njihovoj strukturi pojavile znatno poslije pojave televizije. Ovi tipovi frazeologizacije putem televizije (slike), svjedoče o ulozi cjelokupnog kulturnog iskustva u formiranju frazema. Također, ova vrsta intertekstualnosti potvrđuje da se i o slici može govoriti kao o nečemu što ne predstavlja zatvoreno i samosvojno tkivo jer, do sada se, u kontekstu teorije intertekstualnosti, u tom smislu govorilo samo o tekstu. ${ }^{11}$

b) Frazemi referirani enciklopedijskim znanjem čine drugi krug unutar ove grupe. To su frazemi čije su animalističke komponente ušle u frazeologiju posredstvom tzv. enciklopedijskog znanja, a među njima su npr. medvjed i trut pa se može biti zaštićen kao medvjed 'jako zaštićen' i živjeti kao trut 'biti lijen i nesposoban, živjeti na račun drugih'. Iako je pretpostavljivo da je drugi frazem posredovan iskustvom, polazimo od enciklopedijskog znanja kao ključne uloge u učvršćivanju i frekvenciji frazema, pa je ovdje moguće „preklapanje“ znanstvenog diskursa, udžbeničkog i znanstveno-popularnog, jer je poznato da su osamdesetih godina bile jako gledane dokumentarne emisije koje su tematizirale životinjski svijet. S jedne strane, ova vrsta nenamjerne intertekstualnosti organizira i prenosi znanje poopćavajući ga, a s druge svjedoči i o kreativnom potencijalu znanstvenog diskursa. Izabrano znanje motivira frazeološko značenje, što svjedoči da je bilo koje postavljanje u živi kontekst i diskursne situacije od presudnog značaja za rekreiranja bilo kojeg tipa diskursa ili teksta, a kulturni okvir podrazumijeva umnogome okvir znanja koje imaju učesnici u interakciji.

c) Frazemi eksplicitnih referenci čine poseban, treći krug frazema. Odnosno, kreirani su putem intertekstualne tehnike citatnosti, što znači da su gotovi preuzeti iz nekog drugog teksta, koji sam po sebi u kulturi ima određeno mjesto i značenje. Među takvima je frazem biti kao jazavac pred sudom 'biti zbunjen, ne shvatati situaciju'. Ovdje se radi o naslovu poznatog Kočićevog romana koji je bio, i još uvijek jest, dio obavezne školske lektire, a sam funkcionira kao metafora. U ovoj vrsti rekontekstualizacije nije došlo do promjene značenja u odnosu na značenje teksta romana, tako da frazem tumačimo prema ustaljenoj praksi tumačenja koju nam je u nasljedstvo ostavila ranija interpretativna tradicija. Jezično fiksiranje „učvršćuje“ označeno. Osim toga, ovaj postupak intertekstualnog frazeologiziranja jasno upućuje na otvorenost i fluidnost granica teksta, kao i na složen odnos teksta i konteksta. Ovdje se može govoriti o procesu u kojem jedinica teksta ulazi u ono što je sadržaj konteksta. Tekst (roman u sveukupnosti njegova značenja) 
na ovaj način izlazi i nadilazi školske programe i funkcionira u društvenoj stvarnosti.

d) Frazemi aluzivnih referenci su u četvrtoj grupi. Riječ je o frazemima ostvarenim aluzijama. Oni mogu biti porijeklom iz različitih žanrova, pa čak mogu nastajati na osnovu postojećih frazema, odnosno nastati po uzoru na druge frazeme. Takav je frazem ići kao pas u maglu 'lutati, ići besciljno' nastao prema uzoru na već postojeći frazem ići kao guske u maglu, gdje se prvi javlja tek kao strukturna alternacija. Možemo reći i da se, u ovom slučaju, radi samo o frazemskoj modifikaciji, budući da je zamijenjen samo jedan leksem u strukturi, a nije došlo ni do kakve promjene u značenju. Kako je pas životinja koja se u frazeologiji najčešće javlja kao intenzifikator, onda je takva mogućnost vrlo vjerovatna i u ovom slučaju. Zatim imamo frazem marljiv kao mrav 'jako marljiv, vrijedan', što je ustvari aluzija na poznatu priču o cvrčku i mravu, koja je bila obavezna u predškolskom odgojno-obrazovnom programu, kao i u slikovnicama za djecu, što je bilo pogodna okolnost za formiranje frazema na osnovu ove priče. Tu je i frazem biti kao lisica i kiselo grožđe 'biti licemjeran u nekoj situaciji', a što je opet aluzija na jednu Ezopovu basnu koja je bila obavezna u udžbenicima književnosti - čitankama. Zajednička karakteristika ove vrste poredbenih frazema je znatno snažnija ekspresivnost. I, za razliku od drugih poredbenih frazema, u kojima se, najčešće, potencira neka osobina ili stanje, frazemi-aluzije znatno su sugestivniji u ocjenjivanju situacija, kao i u izražavanju stava, a referiranjem na druge tekstove, možda najbolje podsjećaju koliko je naša stvarnost posredovana. ${ }^{12}$

e) Zatim, tu su i frazemi porijeklom kolokacije. Bitno je naglasiti da su frazemi iz ove grupe prošli fazu okazionalnih kolokacija, a njihov je primarni kontekst bio tekst epskih narodnih pjesama, u kojima su se oblikovali u određeno, specificirano značenje. Među takvima je npr.: cičati (vrištati) kao Damjanov Zelenko 'uporno i tužno vikati, derati se'; prenes. 'žaliti se na nešto'. Frazem je nastao prema stihu čuvene epske pjesme iz kosovskog ciklusa Smrt majke Jugovića, gdje u izvornom tekstu stoji:

(...) Snaho moja, ljubo Damjanova,

što nam vrišti Damjanov zelenko? (...)

Za razliku od drugih epskih pjesama, ova je, također, bila dijelom obaveznih udžbeničkih sadržaja kao primjer jedne od najljepših južnoslavenskih epskih pjesama. Frazem upućuje na jedno od tužnijih mjesta u tekstu pjesme, gdje čak i konj jednog od sinova majke Jugovića žali za gospodarom tako što odbija vodu i hranu, jer to nije ona ista kojom ga je hranio Damjan Jugović, te nam na taj način otkriva nešto o samoj motivaciji frazema. Frazeologizira se sa onim što ima posebno mjesto u kolektivnom pamćenju, a svima je dobro poznato koliko je kosovski mit odredio društveni život i ko-

12 Zanimljivo bi bilo istraživati njihovu upotrebu u drugim diskursima, budući da nose vrlo specifično konotativno značenje. 
lektivnu svijest ovog prostora. Osim toga, ukorijenjenost u frazeološkom fondu svjedoči o funkcionalnosti usmenih predanja, o njihovoj vezanosti za grupe o čijim sudbinama izvještavaju. ${ }^{13}$ One su izuzetno važne jer donose događaje na osnovu kojih se podupire svijest o jedinstvu i posebnosti i pokazuju određeni sense of the past ovog prostora. ${ }^{14}$ Međutim, treba se naglasiti da ovo uopće ne mora značiti „historijsko“ interesovanje za prošlost, nego više interesovanje za legitimiranje, sjećanje, predanje i identitet. ${ }^{15}$ To je, prije svega, svrhovit, pripremljen i profiliran govorni čin kreiran prema govornom senzibilitetu zajednice, koji u toj zajednici ima svoje mjesto, funkciju i značenje. ${ }^{16}$ Takvi stihovani tekstovi, koji su se prenosili i pamtili, bili su prirodni rezervoar gotovih formula koje nije bilo potrebno uvijek nanovo producirati, nego samo reproducirati.

Osim ovog frazema, čije je intertekstualno porijeklo manje-više poznato svima, postoje i frazemi kod kojih izvor nije toliko poznat i jasan. Među njima su, npr.:

- zavijati kao vuk 'govoriti neartikulirano' ili zavijati kao gladni vuci 'opasno ogovarati'. Primarni tekst ovih frazema bio je tekst epskih pjesama. Tako u analiziranom korpusu bilježimo, i to jako često, sljedeće kolokacije, npr.:

(...) Ko se je god tuda oženio

nikakav se nije oženio,

jer su njega izvijali vuci (...). (str. 18, 21., ŽSM)

(...) On zavija ka planinski vuče (...).

(...) Na Mrsinjcu zavijaše vuci,

na granama grakću gavranovi (...). (str. 18., NPMUBIH).

- graktati kao gavran 'dosađivati'

U epskim pjesmama je, također, frekventna ova kolokacija:

(...) viju vuci, grakću gavranovi

prekasuju međedine crne (...), (str. 290., NPMUBIH)

(...) Na Mrsinjcu zavijaše vuci, (str. 193., isto)

na granama grakću gavranovi (...), i:

(...) kad zagrakta gavran ptica crna (...). (str. 264., isto).

Iste potvrde nalazimo $\mathrm{i}$ za frazeme:

- crn kao gavran 'jako crn', gdje u epskom tekstu nalazimo sljedeće kolokacije:

(...) car je na njih okrenuo glavu

kao da mu je crn gavran zasijo (...), ( str. 242., ŽSM)

(...) pocrnio kako gavran crni (...), (str. 200., NPMUBIH)

(...) dok padoše dva crna gavrana (...). (str. 129, 130., isto).

\footnotetext{
13 Shils definiše „historijski smisao“ kao vrstu pranagona, kao elementarnu osobinu čovjeka, a koja je u vezi sa njegovom sposobnošću za kulturu, i navodi da su historijska predanja mnogo više vezana za grupe o čijim sudbinama govore, nego pisani podaci (1981).

14 Prema: Shils 1981.

15 O tome: Asman 2007: 67.

16 Prema: Botica 2013: 13.
} 
Istog su porijekla i frazemi:

- cičati kao zmija 'vrištati, derati se bez razloga', gdje primarni tekst potvrđuje u formi kolokacije kao:

(...) Meho ciknu kao zmija ljuta,

a divojka kako košutica (...); (str. 21,317., ŽSM)

(...) U dorata oko zakrvavi,

cik ga stoji kao zmije ljute (...), (str. 155., ŽSM)

Cura ciči kao ljuta zmija (...); (str. 155., isto).

Prema tekstu epskih pjesama formirani su i frazemi:

- poslužiti kao kurban 'biti žrtvovan', budući da u tekstu epske pjesme nalazimo:

(...) koji bi se junak naložio

pa bi sebe kurban učinio (...); (str. 175., NPMUBIH).

Fidahlije, božje džematlijel

što su sebe kurban učinili! (...); (str. 287., ŽSM). ${ }^{17}$

Isto vrijedi i za frazeme:

- pocrniti kao crna čavka 'izgledati ružno, potamnjeti', jer se u analiziranom korpusu tekstu narodne pjesme redovno pojavljuju kolokacije tipa:

(...) konj do konja, vojnik do vojnika,

kapa šarka kao crna čavka (...). (str. 63., NPMUBIH).

Isto pretpostavljamo i u frazemu:

- biti kao zmaj 'biti zgodan' /o muškarcu/. Tekst različitih pjesama potvrđuje da su samo junake ovako imenovali i to ne bilo koje, nego one koji su posjedovali fizičku ljepotu i koji su dolazili iz uglednijih kuća ili porodica. Tako u pjesmama nalazimo: (...) od hiseta toga zmaja zlatna, od hiseta i velje radosti (...); (str. 229., NPMUBIH)

Čini mi se zmaje gledajući, da su tvome uočili dvoru... (str. 87., NPMUBIH)

(...) za dva zmaja obadva junaka; (str. 81., NPMUBIH)

(...) sad dva zmaja zavikaše Vuku (...)

(...) A na konju momak zmajeviti (...). (str. 21., KJP) itd.

Kao i u drugim tipovima kolokacija, ovdje su riječi vjerovatno ulazile sa svojim prototipnim značenjem. ${ }^{18}$ No, s obzirom na prirodu deseteračkog stiha, vjerovatno su brzo oblikovale konkretno, specificirano značenje. A kako su kolokacije restriktivan i čvrst spoj u odnosu na slobodne sintagme, čini se da je njihov prirodni put i krajnja tačka očvršćivanja upravo forma frazema. Ograničen odabir i mala mogućnost zamjene članova bili su povoljni uvjeti za prelazak u frazemsku formu. Njihovo leksikaliziranje je

\footnotetext{
$\overline{17}$ Ovaj frazem je uvršten iz jednostavnog razloga što je kurban uvijek neka životinja, i to tačno određena: krava, ovan ili ovca.

18 Prema: Firth 1957: 195.
} 
olakšao tip teksta u kojem su producirane, jer je narodna poezija, kao uostalom i sve što pripada usmenoj tradiciji, dio kolektivne svijesti. Svi ovi primjeri svjedoče o tome koliko su referentni tekstovi, a u ovom slučaju tekstovi koji potječu iz usmene tradicije, duboko ukorijenjeni u kulturi, te koliko je ona primarni okvir u nastajanju, kao i u tumačenju, bilo kojeg teksta, ili jedinice teksta. Osim toga, potvrđuju i u kojoj su mjeri kolokacije, formule, frazemi postavljeni na mehanizmima konceptualnog pretapanja. Performans epske pjesme bio je itekako važan, a možda i presudan u njezinu pamćenju i kasnijoj reprodukciji. Ovi frazemi jesu primarno funkcionirali kao primjerene formule i bili su sigurno važno mnemotehničko sredstvo zapamćivanja, ali vremenom je došlo do interferencije između izvođenih pjesama i narodnih govora. Na taj način su se u kolektivnoj svijesti sačuvale formule, samo što je kod nekih značenje bitno modificirano u skladu sa novim kontekstima.

\section{Zaključak}

Ovo je istraživanje pokazalo da je zaista potrebno i u lingvistici, odnosno u frazeologiji razvijati teorijski koncept intertekstualnosti. Jer, otkrivanjem porijekla i motivacije frazema, pozicioniraju se tekstovi u kulturi, a time se doprinosi i u identifikaciji ideja i modela kojima se određena kultura rukovodi. U radu smo pokušali dati i moguću klasifikaciju frazeoloških jedinica s obzirom na primarne, referentne tekstove. Analizirani frazemi - njihovo porijeklo i motivacija - pokazuju koliko su ove jezične jedinice zaista uvjetovane svim jedinicama konteksta. S obzirom na prethodno postavljena pitanja, a na temelju analizirane građe, možemo utvrditi sljedeće:

Prvo. Znatno je više animalističkih poredbenih frazema koji u svojoj strukturi imaju domaće životinje, insekte i poznate glodare, sa kojima su ljudi u našoj kulturi svakodnevno bili u neposrednom odnosu. To, neizravno, upućuje na važnost životnog iskustva u odnosu na bilo što drugo. Drugim riječima, neposredno je iskustvo prvi i najvažniji izvor u procesu frazeologiziranja. Svi ostali izvori dolaze iza ovoga. Čovjek uspoređuje i kreira na osnovu njegovog razumijevanja samog sebe, svijeta i života, kao i njegove uloge i mjesta u tom svijetu. A sama animalistički strukturirana frazeologija činjenica je biocentričnog pluralističkog koncepta.

Drugo. Stupanj ekspresivnosti razlikuje poredbene frazeme sa animalističkom komponentom intertekstualnog porijekla od onih koji to nisu, jer su njihova značenja izrazito metaforična.

Treće. Osim desemantizacije slobodnih veza riječi, kao postupka u tvorbi frazema, postoje i drugi tvorbeni modeli, među koje ubrajamo i ove ostvarene intertekstualnim tehnikama: citatima, aluzijama i signalima, kao i putem kolokacija i formula.

Četvrto. Analizirani korpus sasvim jasno pokazuje da se posuđuje unutar zajedničkog kulturnog iskustva jer je ono neophodno u razumijevanju frazema. No, kako je odnos dvosmjeran, jasno je da se jezičnim učvršćivanjem održavaju određeni mentalni modeli koji onda igraju važne uloge u izgrađivanju svjetonazora.

Peto. Istraživanje implicitno potvrđuje koliko je ovaj prostor bio povoljan kontekst za epske stilizacije i koliko je, pored autentičnog sjećanja, svakodnevno prisutno i važno i ono koje to nije. 
IZVOR:

Mahmutović, Alisa. 2012. Kao frazeološki rječnik (rječnik frazema s poredbenom česticom „kao“). Sarajevo - Zagreb: Dobra knjiga-Sinopsis. [KFR]

\section{GRAĐA:}

Objavljene zbirke epskih narodnih pjesama:

Krajiške junačke pjesme. 1998. Bihać: Biblioteka Ključanin.

Herman, Kosta. 1990. Narodne pjesme Muslimana u Bosni i Hercegovini. [izd. 2] Sarajevo: Svjetlost. [NPMUBIH]

Ženidba Smailagić Mehe. 1987. Sarajevo: Svjetlost. [ŽSM]

\section{LITERATURA}

Asman, Jan. 2007. Kultura pamćenja. Beograd: Prosveta.

Bakhtin, Mikhail. 1981. The Dialogic Imagination. Austin: University of Texas Press.

Barthes, Roland et al. 1982. A Barthes Reader. New York: Hill and Wang.

Botica, Stipe. 2013. Povijest hrvatske usmene književnosti. Zagreb: Školska knjiga.

Bugarski, Ranko. 2013. Kultura i jezik. www.uns.ac.rs./stara/epub/susretkultura/pdf Datum posjeta: 25. 04. 2014.

Burger, Harold et al. 1982. Handbuch der Phraseologie. Berlin: Walter Der Gruyter.

Eagleton, Terry. 2002. Ideja kulture. Zagreb: Naklada Jasenski i Turk.

Fairclough, Norman. 1992. Discourse and Text: Linguistic and Intertextual Analysis within Discourse Analysis. U: Discourse and Society. London: Longman. 193-217.

Fink-Arsovski, Željka. 2002. Poredbena frazeologija: pogled izvana i iznutra. Zagreb: FF press.

Firth, Rupert John. 1957. Language and Languages. Oxford: Oxford University Press.

Goodenough, Ward H. 1964. Cultural Anthropology and Linguistics. U: Language in Culture and Society: A Reader in Linguistics and Anthropology. Hymes, Dell H. (red.). New York: Harper \& Row. 36-39.

Kristeva, Julia. 1986. The Kristeva reader. Oxford: Blackwell.

Lachmann, Rennate. 1990. Gadächtnis und Literatur: Intertextualität in der russischen Moderne. Frankfurt am Main: Suhrkamp.

Lado, Robert. 1957. Linguistics Across Cultures. Ann Arbor MI: University of Michigan Press.

Omazić, Marija. 2008. Processing of Idioms and Idiom Modifications: A View from Cognitive Linguistics. Amsterdam - Philadelphia: John Benjamiss.

Shils, Edward. 1981. Tradition. Chicago: Chicago University Press.

Vidović Bolt, Ivana. 2007. Metaforika zoonima u hrvatskoj frazeologiji. U: Kulturni bestijarij. Marjanić, Suzana; Zaradija Kiš, Antonija (red.). Zagreb: Institut za etnologiju i folkloristiku - Hrvatska sveučilišna naklada. 


\section{RJEČNICI}

Fink Arsovski, Željka et al. 2006. Hrvatsko-slavenski rječnik poredbenih frazema. Zagreb: Knjigra.

\section{SUMMARY}

\section{INTERTEXTUALLY MOTIVATED COMPARATIVE EXPRESSIONS WITH ANIMALISTIC COMPONENT}

This paper deals with comparative expressions with an animalistic component. As a theoretical framework we used the poststructuralist theory of intertextuality. This theory is based on the view that every discourse creates meaning through the interaction with other discourses, which was highly helpful during the analysis of phrases such are language units based in the cultural model of a particular society. Moreover, this theory is based on the importance of the context of each text, so we can talk about the context in the broad and narrow sense. The context in a broader sense implies the entire culture, which again is very important when we refer to phraseology, since the culture here means everything that is created in a society and everything in this society that one has to know or believes in order to act in an acceptable way. That is, we start from the culture as it is defined by Goodenough (1964), who equals the culture and knowledge. Therefore, to analyze phrases means to deal with the essential characteristics of our own culture.

Key words: comparative idioms, intertextuality, text, culture, context 